\title{
Regression Examination of Factors Influencing the Chatbots usage in Banking Industry of India
}

\author{
Deepti Sharma, Amisha Gupta
}

\begin{abstract}
This research investigate the factors influencing the usage of chatbot in banking industry of India. The author used regression analysis to determine and understand the factors influencing the acceptance, usage and adoption of chatbots in banking industry. Data is collected through Primary survey. 100 people were targeted, out of which 72 responded. Once the data is collected in order to check the reliability and validity of data Cronbach Alpha test is performed. The study concludes a significant impact of accessibility on adoption of chatbots. As part of the conclusion author made some suggestions and recommendations discussing the implementation of chatbots in the banking industry of India.
\end{abstract}

Keywords: attitude, chatbots, regression, cronbach alpha test, statistical analysis, descriptive analysis.

\section{INTRODUCTION}

Several new things are happening in the IT industry, but the most recent which the industry is excited about is introduction and launch of chatbots. Many a times it is marked as 4th industrial revolution (Kaplan, 2016). Out of many technological developments machine learning system is making remarkable presence. Right from the middle ages, people created machines that use to give impression of aliveness with the help of technical mechanisms (Mijwel, 2015). Mike Train (2019) explains that it is predicted by,chatbots will be handling no less than $85 \%$ of all customer service interactions at financial institutions.Human Computer interaction is developing day by day. Technically this interaction system is called chatbot. The first such kind of Dialogue system introduced was ELIZA. To be precise chatbots are defined as dialogue systems that communicate using natural language. In later days customer care used to be defined as making calls on hotlines or standing in the long queues. This type of communication is often slow and very much annoying for the customers. With the increasing popularity of bots the system has become much more comfortable.

This paper investigates and analyse the impact of factors influencing the adoption of Chatbots in banking industry of India. Moreover an effort is made to answer how chatbots are been valued differently by different consumers. Although a rich literature review is present for Chatbot industry but its application in banking industry is not been much discussed.

Revised Manuscript Received on July 22, 2019.

Deepti Sharma, Deptt of Information Technology, Jagan Institute of Management Studies, Delhi, India

Amisha Gupta, Deptt of Management, Jagan Institute of Management Studies, Delhi, India.
Furthermore the explored literature review is silent about the impact of factors influencing the adoption of chatbots in banking industry of India.

\section{LITERATURE REVIEW CTION}

Artificial intelligence is bringing lot many changes in the world. Artificial intelligence will power the new banking foundation, Bob Legtur, 2019. The days of standing in queues to avail the banking services sounds an old time. In India Kotak Mahindra was the first bank to introduce chatbots to the banking customers. Their voice chatbot was named "Keya". EVA- an HDFC Banks' chatbot has already answered 5 million queries.

Khan \& Das, 2018 explains chatbot as "an artificially intelligent conversational agent that simulates human-like conversation that, for example, allow users to type questions (i.e., queries) and, in return, generates meaningful answers to these questions." Whether one talks about the purchase or sales, customer is always important. Chatbots helps in delivering value to the customers (Woodruff 1997).Karmark, 2004 explains the dynamic characheterstics of customer focussing on their changing behaviour, needs and requirements. While talking about chatbot, satisfaction of customers and the utility of bots plays a very important role in its adoption (Nunes\&Cespedes 2003).Pirila, 2018 also explains customer's expectation, awareness and utility as some of the prime indicator for the satisfaction and adoption of bots by customers. Lam et al. 2004, recognised constructs like customer satisfaction, trust, convenience and awareness as factors influencing the loyalty and adoption of new product. Security and threat are found to be important factors influencing the adoption of new technology (Tellefsen 2001).Furthermore Shawar\& Atwell, 2014 discussed the impact of accessibility on adoption of chatbot. Richard, Vivensius (2019), directly discuss thefactors influencing the acceptance and usage of chatbots in banking industry of Indonesia . And as an result they explain perceived utility and ease of use as the influencing factors.

\section{METHODOLOGY}

An exploratory study was carried to determine and identify the factors influencing the adoption of chatbot by consumers in banking industry. In depth interviews were conducted. The results show that the factors that are prominent to influence the adoption of chatbot represented by intention to useare: utility, accessibility and threat. The results are further mapped with literature review.

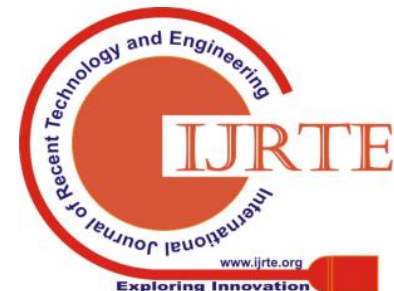


Various secondary sources of data are explored like journals, Internet, magazines and research publications. Primary data is collected with the help of self-designed questionnaires. Survey is conducted through emails, watsapp and Facebook. For valid and reliable results, a random sampling is done including customers of various segments using banking services with a sample size of 100 people. Out of those, 72 people responded. Later, all the incomplete questions from the data collected have been cleaned using Microsoft Excel. After collecting the results the reliability of the variables is checked using Cronbach's Alpha $(\alpha)$ test. Further to analyse how independent factors i.e. utility, accessibility and threat influence dependant variable intention to use, regression analysis was performed. All the factors are given to users (respondents) as questions formulated as different statements to determine the factors influencing the adoption of chatbot by users in banking industry.

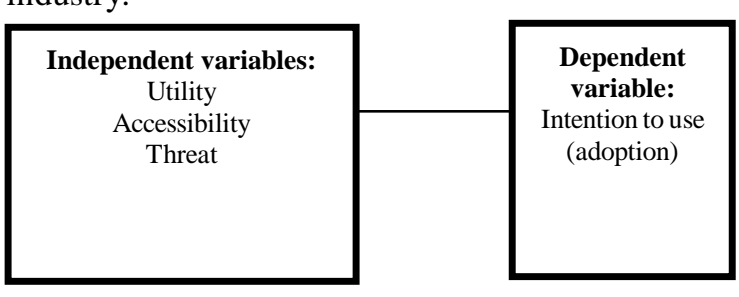

Fig 1. Independent and Dependent Variables

\section{A) Variables}

Independent variables: Utility, accessibility and threat. Utility includes using chatbot as easy to use and easy to process. Accessibility comprises of doing basic banking transaction easily, speedy process and user friendly. Threat covers data security and privacy.

Dependent variable: The dependent variable intention to use includes convenience, curiosity and future technology.

\section{B) Hypothesis}

H1: utility of chatbot influences the adoption of chatbots by consumers.

H2: accessibility of use influences the adoption of chatbots by consumers.

H3: threat to use influences the adoption of chatbots by consumers.

\section{C) Analytical Model}

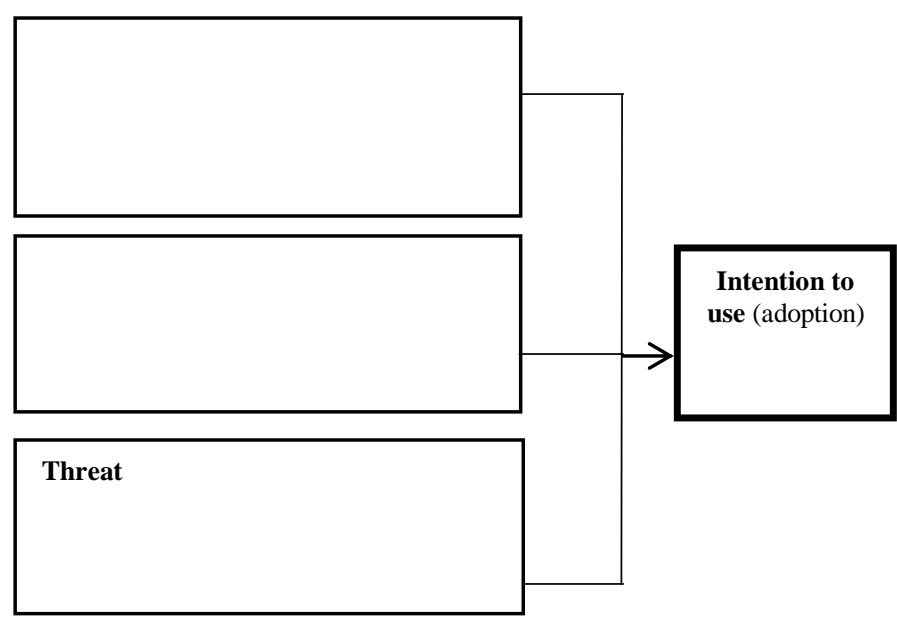

Fig 2.Analytical Model

\section{RESULTS AND ANALYSIS}

The research work has dealt with the question in the ways various factors may influence the intention to use and adopt the chatbot and how chatbot features affect the usage that are valued differently by different users. The relationship between the intention (adoption) to use chatbot and the other independent factors namely; utility, accessibility and threat is analysed. The research questions were very well answered by a descriptive analysis.

The questionnaire for "intention to use" a Chatbot is developed for this research work. Authors have applied Cronbach's Alpha $(\alpha)$ to test internal reliability of the work. The value of Cronbach's Alpha for each factor of the questionnaire portion is shown in table 1 . The overall value of Cronbach's Alpha which is equal to 0.77916 presents good reliability. Thus result shown is of great significance and proves the reliability of the factors and work based on the studied literature.

Table I. Cronbach Alpha for Intention to Use Factor

\begin{tabular}{|l|l|l|}
\hline Dimension & $\begin{array}{l}\text { No.of } \\
\text { Items }\end{array}$ & $\begin{array}{l}\text { Cronbach's } \\
\text { Alpha }\end{array}$ \\
\hline Utility & 3 & .818 \\
\hline Accessibility & 3 & .717 \\
\hline $\begin{array}{l}\text { Threat and } \\
\text { Awareness }\end{array}$ & 3 & .676 \\
\hline
\end{tabular}

Further to analyse how independent factors i.e. utility, accessibility and threat influence dependant variable intention to use, regression analysis was performed. The value of $\mathrm{R}$ square 0.639902282 showed the combined effect of utilization, accessibility and risk, threats on intention (adoption) to use the chatbot. Thus, it can be seen from the results obtained that around $63 \%$ people states that they intend to use chatbot because they find it easy to use, accessible and other factors defined by authors. Furthermore, the individual effect of other independent factors on dependent factor is also shown in table 3 below.

Table III. Summary Output for Independent Factor

\begin{tabular}{|l|l|}
\hline Factor & R SQUARE \\
\hline Utility & .398 \\
\hline Accessibility & .475 \\
\hline Threat & .224 \\
\hline
\end{tabular}

It can be observed from the above table that there is a lot of variation between different factors and there are different opinions and estimations given by consumers. It can be analysed from above table that $39 \%$ consumers' are intended to use chatbot because they find it very easy to use and process. They think that chatbot helps them to engage with the customer service. Furthermore, $47 \%$ consumers' consumers find chatbot easy to

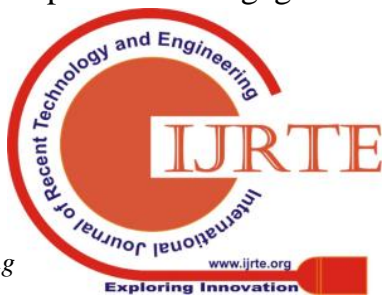


do banking transaction easily. They think it is a speedy process and they feel free to ask any questions from chatbot. It can be further stated that only $22 \%$ consumers' find chatbot risky in terms of data security and privacy.
2. S A. kader, J Woods, Survey on Chatbot Design Techniques in Speech Conversation Systems, IJACSA International Journal of Advanced Computer Science and Applications, 6, 72--80, 2015.

3. Peter Brandtzaeg, \&AsbjørnFølstad, Why people use chatbots, 2017.

4. BI Intelligence, $80 \%$ of businesses want chatbots by $2020,2016$.

5. A. Debecker, Discovering the Types of Chat Bots, 2017.

6. E Candela, Consumers' perception and attitude towards chatbots' adoption. A focus on the Italian market, 2018.

7. E. Kurilchik, Chat bots as a digital marketing tool, 2017

8. Gartner, Making Live Chat a Must-Have Engagement Channel, 2017.

Table II. Descriptive Statistics

\begin{tabular}{|l|r|l|r|l|r|}
\hline \multicolumn{2}{|c|}{ Utility } & \multicolumn{2}{c|}{ Accessibility } & & \\
\hline & & & & \\
\hline Mean & 11.85915493 & Mean & 11.36619718 & Mean & 9.450704 \\
\hline Standard Error & 0.26559661 & Standard Error & 0.252344688 & Standard Error & 0.320204 \\
\hline Median & 12 & Median & 12 & Median & 9 \\
\hline Mode & 12 & Mode & 11 & Mode & 9 \\
\hline Standard Deviation & 2.237956815 & Standard Deviation & 2.126294138 & Standard Deviation & 2.698088 \\
\hline Sample Variance & 5.008450704 & Sample Variance & 4.521126761 & Sample Variance & 7.279678 \\
\hline Kurtosis & -0.445939513 & Kurtosis & -0.043935564 & Kurtosis & -0.00935 \\
\hline Skewness & -0.306442202 & Skewness & -0.478870465 & Skewness & -0.27205 \\
\hline Range & 9 & Range & 9 & Range & 12 \\
\hline Minimum & 6 & Minimum & 6 & Minimum & 3 \\
\hline Maximum & 15 & Maximum & 15 & Maximum & 15 \\
\hline Sum & 842 & Sum & 71 & Count & 671 \\
\hline Count & 71 & Count & 0.503285611 & Level(95.0\%) \\
\hline $\begin{array}{l}\text { Confidence } \\
\text { Level(95.0\%) }\end{array}$ & 0.529715736 & Level(95.0\%) & & 0.638627 \\
\hline
\end{tabular}

Also, they are less aware about chatbot and they are using because their family and friends are using it. Thus, it proves the hypothesis stated above which says utility, accessibility and threat influences the adoption of chatbots by consumers.

\section{ConCLUSION}

The study determines the factors influencing the adoption of chatbots by consumers in the banking industry of India. . A detailed literature review is conducted and it indicates the scope and acceptance for chat bots are increasing. The literature and the exploratory study suggest the factors important for the adoption of chatbots are utility, accessibility and threat. In order to check the reliability of explored independent factors Cronbach Alpha test is conducted and results proves the reliability of the factors and work based on the studied literature. The results explain the significant impact of utility, accessibility and threat on the adoption of chatbots by consumers in banking Industry. Over an all it can be stated that customers are really interested in adoption chatbots for the banking services. The impact of accessibility is relatively found to be significantly higher in comparison to other two independent variables. Focus is required to be paid with respect to threat and security. Henceforth banking industry should be ready for the shift.
9. Oracle, Can Virtual Experiences Replace Reality? Redwood Shores: Oracle Corporation, 2016.

10. B. Shawar, \& E. Atwell, Chatbots: are They really useful? LDV Forum, 22, 29--49, 2007.

11. [11] International Journal of Civil Engineering and Technology (IJCIET), Volume 10, Issue 04, April 2019, pp. 1270-1281, Article ID: IJCIET_10_04

12. [12] R. Richad, V. Vivensius, S. Sfenrianto and Emil R. Kaburuan, Analysis of factors influencing millennial's technology acceptance of Chabot in the banking industry in Indonesia, 2018

13. [13] Mike Train, Chabot's Have Taken Over Banking, So Now What?,

14. Bob Legture ,Prediction,Personatics , 2019

\section{REFERENCES}

1. Accenture, At Your Service: Embracing the Disruptive Power of Chatbots, Dublin: Accenture, 2017 